\title{
On the possibility of using reaction time to study false memories
}

\author{
Ederaldo José Lopes and Ricardo Basso Garcia \\ Universidade Federal de Uberlândia, Uberlândia, MG, Brazil
}

\begin{abstract}
Research on false memories has extensively used the recognition and recollection of lists of semantically associated words, called the Deese-Roediger-McDermott (DRM) paradigm. In the DRM procedure, the measure of accuracy/errors is usually the main dependent variable. In this paper we review research that integrated reaction time measures into the DRM paradigm and discuss the future contributions of measures of reaction time to the understanding of false memories. Keywords: false memory, short-term recognition, reaction time, DRM Paradigm.
\end{abstract}

Received 09 January 2014; received in revised form 18 August 2014; accepted 19 August 2014. Available online 25 November 2014.

\section{Introduction}

In daily life we are constantly required to retrieve information from memory. The ability to store and recover information is crucial for interacting with the environment, solving problems, and planning future actions. A reconstructive process based on schemata supports the recovery of events (Bartlett, 1932; Roediger \& McDermott, 2000; Roediger, McDermott, \& Robinson, 1998) and may result in the inaccurate recollection of events, not only because we forget details or facts, but also because memories may contain distortions that consist of false memories, perceptual illusions, false beliefs, hallucinations, and confabulations (Best \& Intons-Peterson 1998; Roediger \& Gallo, 2004).

False memories are recollections of facts or events that never happened or their occurrence was different from what is recalled and comprise cases in which we believe we have experienced or witnessed events that actually were described to us or we believe that we have already seen an event that is, in fact, new (Alves \& Lopes, 2007; Loftus, 1997; Mazzoni \& Scoboria, 2007; Neufeld, Brust, \& Stein, 2010; Roediger \& McDermott, 2000).

One widespread method of investigating false memories is the experimental procedure known as the Deese-Roediger-McDermott (DRM) paradigm (Deese, 1959; Roediger \& McDermott, 1995), which is based on the effect produced by the degree of semantic association

Ederaldo José Lopes and Ricardo Basso Garcia, Instituto de Psicologia, Universidade Federal de Uberlândia. Correspondence regarding this article should be directed to: Ederaldo José Lopes, Instituto de Psicologia, Universidade Federal de Uberlândia, Av. Maranhão, S/No Sala $2 \mathrm{C} 48$, Campus Umuarama, Uberlândia, MG, 38405-318, Brazil. E-mail: ederaldol@umuarama.ufu.br between words on the formation of false memories. The DRM paradigm consists of presenting lists of words that are related semantically (e.g., toes, shoes, nails). When participants are required to recall exactly the same words that were presented, the typical effect is the recall of items that are semantically associated with the list (e.g., feet), which were not in the original set of words.

Generally, studies that use the DRM paradigm focus on such dependent variables as the probability of false recall or false recognition, output position in false recall, the probability of correct responses, and confidence (Roediger et al., 1998). However, a few studies have reported measures of reaction time in the recognition of items that did or did not belong to the DRM lists. In the present paper, we review such studies to discuss the future contributions of reaction time to the understanding of false memories and highlight that reaction time might be an overlooked dependent variable in false memory research.

\section{False memories and reaction time in the DRM paradigm}

Reaction time can be defined as the time that elapses from the input of a stimulus to the output of a response, and it is a powerful way to relate physical events to mental events and basic cognitive processes (Galera \& Lopes, 1995; Luce, 1986; McNicol \& Stewart, 1980; Posner, 1978; Welford, 1980). In the field of cognitive psychology, reaction time has been widely used within the information processing framework, and it is an important measure in studies of perception, attention, and memory (Posner, 1978; Welford, 1980).

Notwithstanding the importance of reaction time in cognitive psychology, few studies of false memories have reported reaction times. One methodological issue 
is that reaction time requires specific instructions (e.g., avoid making mistakes and respond as fast as possible). In the DRM procedure described by Roediger and McDermott (1995), participants were tested in a group setting and were asked to write down all of the words they could remember in the recall task. Afterward, in the recognition task, the participants read words on a sheet and marked their responses to each item (Roediger $\&$ McDermott, 1995). Such procedures are not suitable for response time measurement; instead, a recognition procedure under controlled conditions and individual testing would be more appropriate for measuring reaction time. Although subsequent research has often used computerized procedures in which response times are recorded, this was not followed by an interest in describing or analyzing response time patterns, especially in recognition tasks.

In standard old/new recognition tasks, participants provide yes/no responses to test stimuli. That is, they have to respond whether a given test stimulus is old ("yes") or new ("no"; Radvansky, 2006). In a recognition task, such as the Sternberg task (Sternberg, 1966), participants first memorize a list of items. After a brief delay, one item (i.e., the test stimulus) is presented, and the participants are required to respond as fast as possible whether it does or does not belong to the memorized list. Notably, the Sternberg task is a shortterm recognition procedure with a brief delay between presentation of the initial list and the test stimulus. In the Sternberg (1966) study, the independent variable was the number of memorized stimuli (set size), and the dependent variable was reaction time. The results showed that the mean reaction time increased linearly with the increasing number of memorized stimuli, reflected by the positive slope of the regression line. Additionally, such an increase did not depend on whether the test stimulus was present (positive responses) or absent (negative responses; Burle \& Bonnet, 2000; Sternberg, 1975). This was taken as evidence of a serial and exhaustive information search process that is held in short-term memory in which every item that is stored in memory is checked, even when a target item has already been found (Sternberg, 1966, 1975).

Our goal is to investigate the possibility of using reaction time measures in false memory research. Considering the fact that reaction time has been used in short-term and recognition memory tasks, we performed a search of the PsycINFO database for the terms "reaction time" and "false memory" and "short-term memory" in the keywords search field, with publication dates of 1950 to 2014 . The only paper that combined the three keywords was Coane, McBride, Raulerson, and Jordan (2007).

Coane et al. (2007) reported experiments based on the Sternberg procedure in which participants studied three, five, or seven items of DRM lists and had to respond whether the target stimuli did or did not belong to the memorized lists. Coane et. al. (2007) made some adaptations to integrate the DRM paradigm into the Sternberg task. First, DRM words appeared only once during the experiments. Second, each DRM list was studied four times (Experiment 1) and three times (Experiment 2) prior to testing. Third, contrary to the original Sternberg task, in which "yes" and "no" responses were balanced $(50 \% / 50 \%$ of the trials), "no" responses were more frequent than "yes" responses, representing $75 \%$ of the trials in Experiment 1 and $66 \%$ of the trials in Experiment 2. In fact, in Experiment 1, "no" responses included three probe types: critical lures, list non-studied, and unrelated items. In Experiment 2, "no" responses included two probe types: critical lures and list non-studied.

The main results reported by Coane et al. (2007) were that items that had a strong semantic association with the DRM lists (critical lures) were falsely recognized more often than items that had a weak association with the lists. Additionally, the reaction times in rejecting critical lures were slower than the reaction times in rejecting items with weak associations. These results were interpreted from the perspective of activation/monitoring theories (Roediger, Balota, \& Watson, 2001). Items with stronger semantic associations appeared to require a rechecking process related to the list, implying a greater demand of cognitive resources and reflected by an increase in reaction time (Coane et al., 2007).

The study by Sene, Lopes, and Rossini (in press) replicated the results reported by Coane et al. (2007). DRM lists with three, five, and seven words were presented for $750 \mathrm{~ms}$ in a Sternberg task, with a retention interval of $250 \mathrm{~ms}$. The results were consistent with those reported by Coane et al. (2007), showing that the rejection of associated items was slower than the rejection of unrelated items and true items. Additionally, the analysis of errors showed a higher rate of false memories for lists with seven words than for lists with three words, indicating the influence of memory load on the formation of false memories.

Other studies on false memories have also measured reaction time. Tun, Wingfield, Rosen, and Blanchard (1998) performed experiments with free recall and the old/new recognition of DRM lists. They showed that both younger and older adults presented similar rates of false recognition when test conditions allowed the use of strategies based on gist information. The participants were equally fast in making decisions. When gist strategies were not emphasized, older adults were faster than younger adults and more likely to recognize items that had strong and weak associations with the studied lists.

In the study by Jou, Matus, Aldridge, Rogers, and Zimmerman (2004), the comparison between reaction times in an old/new recognition task revealed that responses to test stimuli that were not in the memorized list were significantly slower than responses to stimuli that were in the list. This result was further extended by Jou (2008), who investigated differences in latencies between false and true memories in a free recall task. The 
results showed a higher latency for false memories than for true memories, leading to the conclusion that it is a weaker form of memory despite its vivid characteristics.

Atkins and Reuter-Lorenz (2008) reported results from a working memory procedure. Four semantically related words were presented for a brief period of time, and participants were tested in an old/new recognition task after a retention interval of 3 or $4 \mathrm{~s}$. The results showed that the reaction time for associated probes (false memories) was approximately $100 \mathrm{~ms}$ slower compared with the other types of probe items.

\section{Discussion and conclusions}

In the present paper we reviewed research that adapted the DRM procedure to measure reaction time in the study of false memories. Our search of the PsycINFO database revealed that the study of false memories in short-term recognition is not very common, especially with typical experimental instructions in which participants had to avoid mistakes and respond as fast as possible.

The studies reviewed herein suggest that reaction time in short-term recognition using DRM lists is an interesting issue to address, with potential contributions to the understanding of false memories. The studies generally revealed an increase in reaction time when new test stimuli were related semantically to the studied list, and the responses were faster for unrelated stimuli or old stimuli. These data indicate that associated items represent a challenge for memory even in the shortterm. False memories may also be related to associative processes during the encoding of information, in addition to reconstructive processes involved in retrieval (Geng, Qi, Li, Fan, Wu, \& Zhu, 2007).

In the Sternberg task with DRM lists, at least two factors appear to influence the encoding of information, namely, the degree of semantic association between the words and the number of words presented for memorization (set size). Despite some classic works that showed that phonological information is the crucial variable in short-term recognition and recall (Baddeley, 1966; Baddeley \& Levy, 1971; Conrad \& Hull, 1964), semantic information is also readily activated and available (Atkins \& Reuter-Lorenz, 2011; Bartha, Martin, \& Jensen, 1998; Haarmann \& Usher, 2001; Jones \& Anderson, 1982; Martin \& Romani, 1994; Martin \& Saffran, 1992; Potter, 1993; Schneider \& Detweiler, 1987; Shulman, 1972). This is consistent with the view that false memories involve implicit associations during the encoding process (Hancock, Hicks, Marsh, \& Ritschel, 2003).

The effect of semantic associations on memory is central to false memory research. According to Roediger and Gallo (2004), two types of theories may account for the DRM effect. Associative theories assume that the associative strength between the items may elicit a critical lure in which the presentation of related words for memorization produces the widespread activation of words within the same semantic field and can activate the mental representation of a word that was not in the list. During the test phase, false memories may occur because of monitoring errors (Johnson, Hashtroudi, \& Lindsay, 1993). In similarity-based theories, such as the fuzzy-trace theory (Brainerd \& Reyna, 2005), DRM lists are assumed to generate two types of traces: a verbatim trace (item-specific information) and a gist trace (thematic information). In the testing phase, words that are consistent with the gist are highly familiar and thus are prone to be falsely recalled. Roediger, Watson, McDermott, and Gallo (2001) showed that two of seven factors (the associative connection between the study words and critical lure and recallability of the lists) explained $84 \%$ of the variance. Thus, associative strength is well established to predict the DRM effect (Roediger \& Gallo, 2004; Roediger et al., 2001).

Another important factor in the formation of false memories is list length (i.e., the number of associates presented for memorization). For example, the rate of false recognition increases when lists have different items compared with lists of repeated items (Hall \& Kozloff, 1973). Hintzman (1988) showed that an increase in list length resulted in a linear increase in false recognition. With regard to DRM, Robinson and Roediger (1997) varied the number of associates presented for memorization (the lists were $3,6,9,12$, or 15 items long) and the mean associative strength of the lists, so that shorter lists had higher mean associative strengths. Contrary to their prediction, higher rates of false recall were observed with longer lists but not with higher mean associative strength. The study by Gallo and Roediger (2003) also varied the number of associates presented for memorization and found effects of length, suggesting that the presentation of more associates increases the associative activation of items related to the lists. Thus, together with associative strength, the list length of associates is an important factor in DRM.

In addition to associative strength and list length, many other factors related to the DRM task have been investigated, such as word length, frequency, concreteness, the presentation rate of study items, the random/blocked presentation of multiple lists, the repetition of study lists, divided attention with a concurrent task, and the retention interval between the study and test, among others (Roediger et al., 1998; Roediger et al., 2001). However, the effects of item characteristics, list properties, and testing conditions on reaction time are still unknown, mainly because the studies focused on other quantitative and qualitative measures. Given the importance of reaction time in the development of theories of cognitive processes, it has been an overlooked measure in false memory research.

What can reaction time reveal about false memories? To answer this question, we should depart from a broader context of memory research and consider the use of reaction time, specifically in the Sternberg recognition task in which reaction time may contribute to a better understanding of different processing stages. 
It is worth noting the following statement by McNicol and Stewart (1980):

The most important new insight (...) is that retrieval involves sampling evidence from an ambiguous memory trace in an attempt to discover whether it contains some relevant information. The degree of noise in the trace apparently depends on factors known to memory researchers for a long time; interference due to the number of other items in the list, or to the lag between an item's presentation and testing. Thus theories of retrieval based on reaction time measures begin to make contact again with an older memory literature where the emphasis was on interference, forgetting and errors. (p. 303)

This quotation illustrates our discussion in the present paper. Research on false memories may also include memory processes that have been investigated using reaction time in the broader context of memory research. Our appeal is to use reaction time in addition to other widespread measures. Accuracy, error rate, and time measures are all fundamental to gain a better understanding of cognitive processes involved in false memories.

One aspect to consider is that reaction time allows statistical analyses beyond the mean, such as variance, skewness, and kurtosis, and can be useful to discriminate different models of processing stages and memory retrieval (McNicol \& Stewart, 1980; Sternberg, 1969, 1975). According to the additive factor method (Sternberg, 1969), analyses of reaction time may be conducted at three different levels: predictions about mean reaction time, predictions about higher moments around the mean, and predictions about the global distribution of reaction time. The additive factor method is based on the effects produced by the experimental manipulation of factors on reaction times. When factors affect reaction time independently, their effects on reaction time are additive and considered to influence different processing stages. When factors interact, their effects are not additive and are considered to influence at least one stage in common (Sternberg, 1969).

The use of reaction time can address important issues concerning false memories, such as whether the locus of the DRM effect is during encoding or retrieval. Based on the additive factor method (Sternberg, 1969), manipulating such experimental factors as set size and the probability of positive and negative responses (e.g., for critical lures) and verifying the patterns of interaction/additivity of such factors are possible. In this model, the function set size $\times$ reaction time is linear. The intercept indicates encoding and response selection processes, and the slope indicates comparison processes between the test stimulus and memorized items. Thus, the reaction time function allows investigations of the relationship between set size (i.e., memory load of associates) and the probability of false recognition. The interaction between these factors should indicate effects on common processing stages, whereas additivity should indicate effects on different stages.

Another important aspect concerns the speedaccuracy trade-off. Experiments that use reaction time measures involve specific instructions to respond as fast as possible and avoid errors. Participants may respond faster with higher error rates or may respond slower with lower error rates. The speed-accuracy trade-off was acknowledged by Thurstone (1937) in discrimination tasks. The Sternberg task involves more than stimulus discrimination, and the linear relationship between set size and reaction times for both positive and negative responses may reveal additional information about the rejection of critical lures and false recognition. The results from Coane et al. (2007) and Sene et al. (in press) showed slower reaction times in the rejection of critical lures and an increase in false recognition. No evidence of a speed-accuracy trade-off was found. This result indicates that the processing of critical lures has some specificities compared with the processing of other types of stimuli that are used in the Sternberg task, such as digits, letters, and unrelated words. This kind of observation is not possible when only the proportion of false memories is taken into consideration. Thus, the use of both accuracy and time measures appears advantageous to extend DRM findings.

In summary, the studies reviewed herein show that related items increase reaction time compared with both unrelated or target items. This indicates that false memories are reflected by reaction times, and this measure may contribute to a better understanding of the formation of false memories. This measure has specific methodological requirements, such as individual testing, controlled conditions for stimulus presentation and response collection, and instructions to respond accurately and as fast as possible. We would like to emphasize that such measures as reaction time and response latency may be better explored in future studies that use the recognition and recall of DRM lists. Since the seminal work by Roediger and McDermott (1995), many factors related to the DRM task have been investigated, and the time taken by participants to falsely recognize or recall nonpresented items has been an overlooked variable in DRM studies.

\section{Acknowledgements}

We would like to thank K. Andrew DeSoto (Washington University, St. Louis, MO, USA) and an anonymous reviewer for the valuable comments and suggestions to improve the manuscript and Jennifer $\mathrm{H}$. Coane (Colby College, Waterville, ME, USA) for the methodological clarifications about the Sternberg task and DRM procedure. We also acknowledge financial support from Conselho Nacional de Desenvolvimento Científico e Tecnológico (CNPq) and Fundação de Amparo à Pesquisa de Minas Gerais (FAPEMIG) to the first author and Coordenação de Aperfeiçoamento de Pessoal de Nível Superior (CAPES) for the PNDP postdoctoral scholarship to the second author. 


\section{References}

Alves, C. M., \& Lopes, E. J. (2007). Falsas memórias: questões teórico-metodológicas. Paidéia, 17(36), 45-56.

Atkins, A. S., \& Reuter-Lorenz, P. A. (2008). False working memories? Semantic distortion in a mere 4 seconds. Memory and Cognition, $36(1), 74-81$

Atkins, A. S., \& Reuter-Lorenz, P. A. (2011). Neural mechanisms of semantic interference and false recognition in short-term memory. Neuroimage, 56(3), 1726-1734.

Baddeley, A. D. (1966). The influence of acoustic and semantic similarity on long-term memory for word sequences. Quarterly Journal of Experimental Psychology, 18(4), 302-309.

Baddeley, A. D., \& Levy, B. A. (1971). Semantic coding and short-term memory. Journal of Experimental Psychology, 89(1), 132-136.

Bartha, M. C., Martin, R. C., \& Jensen, C. R. (1998). Multiple interference effects in short-term recognition memory. American Journal of Psychology, 111(1), 89-118.

Bartlett, F. C. (1932). Remembering: a study in experimental and social psychology. New York: Cambridge University Press.

Best, D. L., \& Intons-Peterson, M. J. (1998). Memory distortions and their prevention. Mahwah: Lawrence Erlbaum.

Brainerd, C. J., \& Reyna, V. F. (2005). The science of false memory. New York: Oxford University Press.

Burle, B., \& Bonnet, M. (2000). High-speed memory scanning: a behavioral argument for a serial oscillatory model. Cognitive Brain Research, 9(3), 327-337.

Coane, J. H., McBride, D. M., Raulerson, B., 3rd, \& Jordan, J. S. (2007). False memory in a short-term memory task. Experimental Psychology, 54(1), 62-70.

Conrad, R., \& Hull, A. J. (1964). Information, acoustic confusion and memory span. British Journal of Psychology, 55(4), 429-432.

Deese, J. (1959). On the predictions of occurrence of particular verbal intrusions in immediate recall. Journal of Experimental Psychology, 58(1), 17-22.

Galera, C., \& Lopes, E. J. (1995). Cronometria de processos mentais. Temas em Psicologia, 3(3), 1-10.

Gallo, D. A., \& Roediger, H.L., III (2003). The effects of associations and aging on illusory recollection. Memory and Cognition, 31(7), 1036-1044.

Geng, H., Qi, Y., Li, Y., Fan, S., Wu, Y., \& Zhu, Y. (2007) Neurophysiological correlates of memory illusion in both encoding and retrieval phases. Brain Research, 1136, 154-168.

Haarmann, H., \& Usher, M. (2001). Maintenance of semantic information in capacity-limited item short-term memory. Psychonomic Bulletin and Review, 8(3), 568-578.

Hall, J. W., \& Kozloff, E. E. (1973). False recognitions of associates of converging versus repeated words. American Journal of Psychology, 86(1), 133-139.

Hancock, T. W., Hicks, J. L., Marsh, R. L., \& Ritschel, L. (2003). Measuring the activation level of critical lures in the DeeseRoediger-McDermott paradigm. American Journal of Psychology, $116(1), 1-14$

Hintzman, D. L. (1988). Judgments of frequency and recognition memory in a multiple-trace memory model. Psychological Review, 95(4), 528-551.

Johnson, M. K., Hashtroudi, S., \& Lindsay, D. S. (1993). Source monitoring. Psychological Bulletin, 114(1), 3-28.

Jones, W. P., \& Anderson, J. R. (1982). Semantic categorization and high-speed scanning. Journal of Experimental Psychology: Learning, Memory, and Cognition, 8(3), 237-242.

Jou, J. (2008). Recall latencies, confidence, and output positions of true and false memories: implications for recall and metamemory theories. Journal of Memory and Language, 58(4), 1049-1064.

Jou, J., Matus, Y. E., Aldridge, J. W., Rogers, D. M., \& Zimmerman, R. L. (2004). How similar is false recognition to veridical recognition objectively and subjectively? Memory and Cognition, 32(5), 824-840.

Loftus, E. F. (1997). Creating false memories. Scientific American, 277(3), 70-75.

Luce, R. D. (1986). Response times: their role in inferring elementary mental organization. New York: Oxford University Press.
Martin, N., \& Saffran, E. (1992). A computational account of deep dysphasia: evidence from a single case study. Brain and Language, 43(2), 240-274.

Martin, R. C., \& Romani, C. (1994). Verbal working memory and sentence comprehension: a multiple-components view. Neuropsychology, 8(4), 506-523.

Mazzoni, G., \& Scoboria, A. (2007). False memories. In: F. T. Durso, R. S. Nickerson, S. T. Dumais, S. Lewandowsky, \& T. J. Perfect (Eds.), Handbook of Applied Cognition (2nd ed, pp. 787-813). Chichester: John Wiley.

McNicol, D., \& Stewart, G. W. (1980). Reaction time and the study of memory. In: A. T. Welford, \& J. M. T. Brebner (Ed.), Reaction times (pp. 253-307). London: Academic Press.

Neufeld, C. B., Brust, P. G., \& Stein, L. M. (2010). Compreendendo o fenômeno das falsas memórias. In: L. M. Stein (Ed.), Falsas memórias: fundamentos científicos e suas aplicações clínicas e jurídicas (pp. 21-41). Porto Alegre: Artmed.

Posner, M. I. (1978). Chronometric explorations of mind. Hillsdale: Lawrence Erlbaum.

Potter, M. C. (1993). Very short-term conceptual memory. Memory and Cognition, 21(2), 156-161.

Radvansky, G. A. (2006). Human memory. Boston: Pearson.

Robinson, K. J., \& Roediger, H.L., III (1997). Associative processes in false recall and false recognition. Psychological Science, 8(3), 231-237.

Roediger, H. L., \& Gallo, D. (2004). Associative memory illusions. In: R.F. Pohl (Ed.), Cognitive illusions: a handbook on fallacies and biases in thinking, judgment and memory (pp. 309-326). Hove: Psychology Press.

Roediger, H. L., \& McDermott, K. B. (1995). Creating false memories: remembering words not presented in lists. Journal of Experimental Psychology: Learning, Memory, and Cognition, 21(4), 803-814.

Roediger, H. L., \& McDermott, K. B. (2000). Distortions of memory. In: E. Tulving, \& F. I. M. Craik (Eds.), The Oxford handbook of memory (pp. 149-162). Oxford: Oxford University Press.

Roediger, H.L., III, Watson, J. M., McDermott, K. B., \& Gallo, D. A. (2001). Factors that determine false recall: a multiple regression analysis. Psychonomic Bulletin and Review, 8(3), 385-407.

Roediger, H. L., Balota, D. A., \& Watson, J. M. (2001). Spreading activation and arousal of false memories. In: R. G., Crowder, \& H. L. Roediger (Eds.), The nature of remembering: essays in honor of Robert G. Crowder (pp. 95-115). Washington, DC: American Psychological Association.

Roediger, H. L., McDermott, K. B., \& Robinson, K. J. (1998). The role of associative processes in creating false memories. In: $\mathrm{M}$. A. Conway, S. E. Gathercole, \& C. Cornoldi (Eds.), Theories of memory (vol. II, pp. 187-245). Hove, UK: Psychology Press.

Schneider, W., \& Detweiler, M. (1987). A connectionist/control architecture for working memory. In: G. H. Bower (Ed.), The psychology of learning and motivation: advances in research and theory (pp. 54-119). New York: Academic Press.

Sene, A. S., Lopes, E. J., \& Rossini, J. C. (in press). Falsas memórias e tempo de reação: estudo com o procedimento de palavras associadas. Psychologica (Coimbra).

Shulman, H. G. (1972). Semantic confusion errors in short-term memory. Journal of Verbal Learning and Verbal Behavior, 11(2), 221-227.

Sternberg, S. (1966). High-speed scanning in human memory. Science, 153(3736), 652-654

Sternberg, S. (1969). The discovery of processing stages: extensions of Donders' method. Acta Psychologica, 30, 276-315.

Sternberg, S. (1975). Memory scanning: new findings and current controversies. Quarterly Journal of Experimental Psychology, 27(1), 1-32.

Thurstone, L. L. (1937). Ability, motivation, and speed. Psychometrika, 2(4), 249-254

Tun, P. A., Wingfield, A., Rosen, M. J., \& Blanchard, L. (1998). Response latencies for false memories: gist-based processes in normal aging. Psychology and Aging, 13(2), 230-241.

Welford, A. T. (1980). Reaction times. New York: Academic Press. 